\title{
KMTNet 시험운영 서버 구축 CONSTRUCTION OF TEST SERVERS FOR KMTNet DATA MANAGEMENT
}

\author{
김동진, 이충욱, 김승리 \\ 한국천문연구원 \\ D. -J. KiM, C. -U. LEE, AND S. -L. KIM \\ Korea Astronomy and Space Science Institute, Daejeon 305-348, Korea \\ E-mail: keaton03@kasi.re.kr \\ (Received 17 November, 2011; Accepted 07 December, 2011)
}

\begin{abstract}
We constructed two test server systems for KMTNet data management. One is the photometry database server which is optimized for stable operation, and the other is the photometric data process server which is optimized for fast I/O between devices. The performances of servers and data storage units were tested using various methods. Database upload was also checked using five different methods. From tests, we concluded that the most efficient method to upload photometric data processing results to database is the use of three nodes with job scheduler under the InnoDB engine. In this study we provide the test results for prototype servers for KMTNet data management.
\end{abstract}

Key words: instrument; data reduction; KMTNet: database

\section{1. 서론}

Wolszczan \& Frail(1992)에 의해 태양계 밖에 있는 외계 행성의 존재가 최초로 확인된 이후, 2011년 11월 현재 약 700여개의 외계행성이 발견되는(Schneider et al., 2011) 등 천체관측기기의 발달에 따라 외계행성 탐색관 측이 국제적으로 매우 활발히 진행되고 있다.

한국천문연구원에서는 미시중력렌즈 방법을 이용한 지구형 외계행성 탐색을 목표로, 2009년부터 외계행성 탐색시스템(Korea Microlensing Telescope Network; KMTNet) 개발 사업을 진행하고 있다. 이 사업에서는 직경 $1.6 \mathrm{~m}$ 광시야 광학망원경과 3.4 억 화소의 모자이 크 CCD 카메라로 이루어진 광시야 관측시스템을 제작 하고 있으며, 이 시스템을 이용하여 얻어질 대용량의 관측 자료를 전송하고 처리하기 위한 측광 파이프라인 시스템과 측광 데이터베이스 시스템도 함께 개발 중이 다.

외계행성 탐색시스템은 2013년과 2014년에 남반구의 칠레, 남아공화국과 호주에 각각 $1,2,3$ 호기가 건설될 예정이다. 이 시스템으로 얻어질 대용량의 관측 자료는 국내로 전송되어 자료처리 및 분석 과정을 거칠 것이 다. 이를 위해 대용량 자료처리 파이프라인과 측광 데 이터베이스에 필요한 핵심루틴을 개발했으며(김동진
등, 2009, 2011; Lee et al., 2010), 모의자료를 이용한 시 험운영을 통하여 이들 프로그램이 정상 작동하는지 확 인할 필요가 있다. 즉, 실제 운영에 사용할 시스템을 사 전에 구축하여 우리가 개발한 소프트웨어가 정상 작동 하는지, 하드웨어가 제 성능을 내는지, 자료 흐름상의 모든 작업이 정상적인지 확인하여야 한다.

시험운영을 위해서는 소프트웨어 개발단계부터 시스 템을 구축해야 하는 비용적인 부담이 있지만, 도입하고 자 하는 하드웨어 상호간의 호환성 문제를 파악하고 수 치상의 성능이 아닌 실제 체감 성능을 파악하여 소프트 웨어 개발에도 참조할 수 있는 장점이 있다. 또한 운영 시 발생할 수 있는 다양한 문제점을 미리 확인하여 실 제 자료처리가 시작되었을 때 동일한 문제가 발생되지 않도록 할 수 있다.

이 연구에서는 측광 데이터베이스 시스템과 측광 파 이프라인 시스템의 시험운영을 위한 시스템을 구축하 고, $\mathrm{MOA}$ (Microlensing Observations in Astrophysics; Bond et al., 2001) 그룹의 실제 측광자료를 기반으로 생 성한 5년간의 가상 측광 파일로 시험운영 서버의 성능 이 충분한지 알아보려고 한다. 이를 위해 시험운영 서 버의 특성과 성능을 조사하고, 운영체제와의 호환성 문 제 및 기타 운영상에 문제가 없는지 평가하였다. 2장에 서는 구축한 시험운영 서버, 외부 저장장치, 테이프 백 
업장치 및 파일전송 프로그램에 대하여 기술하고, 3장 에서는 구축한 시험운영 서버에서 5년간의 측광자료를 저장하였을 경우 데이터베이스의 성능을 기술한다.

\section{2. 시험운영 서버 구성}

KMTNet은 3 대의 $18 \mathrm{~K} \times 18 \mathrm{~K}$ CCD 카메라로 우리 은하 중심방향 $4^{\circ} \times 4^{\circ}$ 영역을 24 시간 연속 관측하며, 하루 동안 생성될 관측 자료의 양은 약 $570 \mathrm{~GB}$ 로 5 년간 570 $\mathrm{TB}$ 의 자료가 생성될 예정이다. 관측 자료는 네트워크나 저장매체를 통하여 한국천문연구원으로 바로 전송 할 것으로, 각 관측소는 $16 \mathrm{~TB}$ 의 저장장치를 설치하여 2 달 동안의 자료를 보관하여 자료 전송 시 저장매체의 분실이 발생하면 즉각 대처할 수 있도록 하였다. 이렇 게 한국천문연구원에 수집된 관측 자료는 백업과 동시 에 측광 자료처리가 진행 될 것이다. 처리된 측광 자료 는 데이터베이스에 저장하여 언제든지 검색하여 자료를 분석할 수 있도록 한다. 5년 동안 데이터베이스에 저장 할 측광 결과는 약 $300 \mathrm{~TB}$ 정도가 될 것으로 예측된다. 3 대의 관측시스템을 이용하여 24시간 연속 관측을 수행하면, OGLE(Optical Gravitational Lensing Experiment; Udalski et al., 2008)이나 MOA 그룹과 같이, 흥미로운 천체의 후속(follow-up) 관측을 위한 실시간 알람을 제공할 수 있다. 그러나 이를 위해서는 대용량 의 자료를 빠른 시간 내에 처리하기 위한 고성능의 시 스템이 필수적이다. 이러한 현업 시스템을 운영하기 전 에 시스템을 미리 구축하여 성능과 한계를 파악할 필요 가 있다. 이렇게 도입한 시험운영 서버는 시험운영이 종료되면 도출된 각종 문제점을 보완하여 현업 장비로 전환한다. 이 장에서는 KMTNet에서 사용할 시험운영 서버의 사양과 기능에 대해서 기술한다.

\section{1. 파이프라인 서버와 데이터베이스 서버}

KMTNet 측광 파이프라인 시스템과 측광 데이터베이스 시스템은 관측 자료를 빠른 시간에 전송하고 측광 처리 하여 데이터베이스에 입력한 후 원하는 결과를 추출할 수 있어야 한다. 두 시스템은 필요할 경우 자원을 공유 할 수 있도록 동일한 $\mathrm{CPU}$ 성능과 네트워크 전송대역폭 을 가지고 있지만 데이터베이스 시스템은 안정성을 기 반으로 자료의 업로드 및 검색 속도 등이 KMTNet 프 레임워크 개발 서버(김동진 등, 2011)를 기준으로 더욱 빠른 성능을 가지도록 구성하였고, 파이프라인 시스템 은 네트워크를 통한 관측 이미지 전송 및 저장이 기존 의 측광파이프라인 개발 서버(이충욱 등, 2009)보다 빠 른 성능을 가지도록 구성하였다. 그림 1은 이번 연구를 위해 구성한 KMTNet 시험운영 서버의 모습이다.

측광 데이터베이스 시스템은 데이터베이스가 작동하 는 동안 순간정전과 같은 돌발 상황을 방지하기 위해

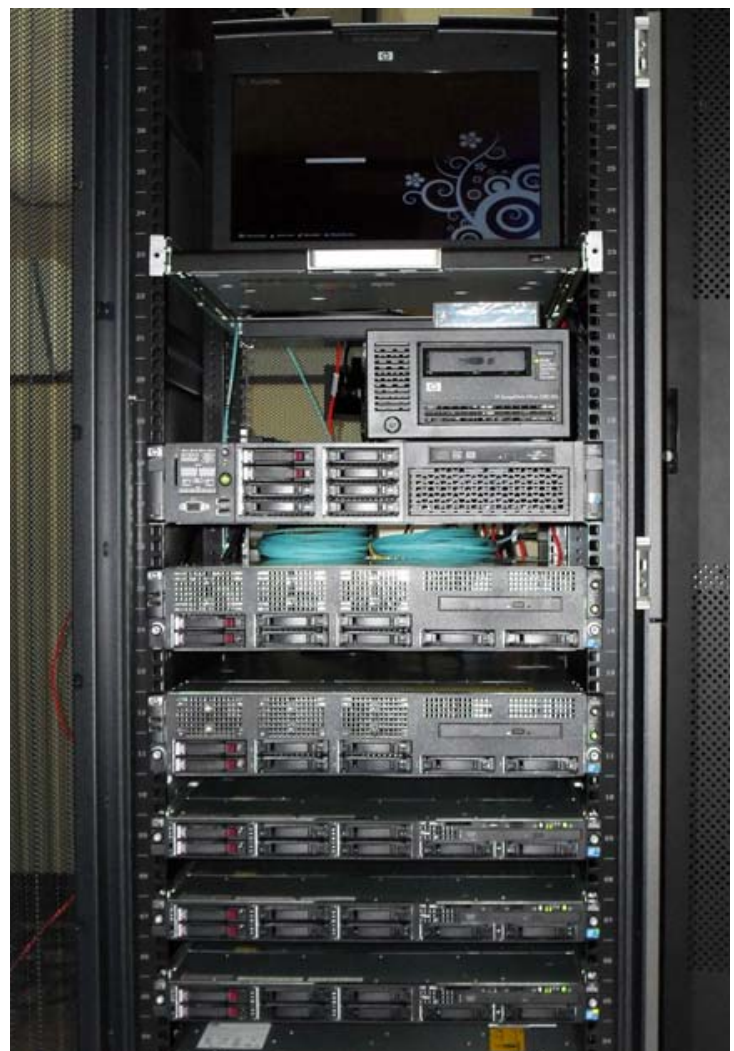

그림 1. KMTNet 시험운영 서버. 3대의 데이터베 이스 서버와 3 대의 파이프라인 서버, $16 \mathrm{~TB}$ 저장장치와 LTO-5 테이프로 구성되었다.

전원을 2 중화 하였다. 시스템이 갑작스레 꺼질 경우 데 이터베이스 파일이 손상될 수 있고 복구에 상당한 시간 을 소비해야 하기 때문에 안정적인 전원 공급이 필요하 다. 따라서 데이터베이스 시스템에 전원공급장치(Power Supply Unit; PSU)를 2개씩 장착하고, 각각의 $\mathrm{PSU}$ 에는 독립된 차단기에서 분배된 전원이 인가되도록 하였다. PSU에 무정전 전원장치(Uninterruptible Power Supply; UPS)를 연결하면 순간 정전이나 장시간 정전이 발생하 였을 경우 서버 다운으로 인한 데이터베이스 손상을 막 을 수 있다. UPS는 관측시스템 1 호기가 완성되고 시험 관측이 들어가기 전에 장착할 계획이다. 그리고 정전이 발생하거나 정전 이외 문제로 서버의 정상 운영이 불가 능할 경우 외부에서 원격으로 접속하여 전원을 끄고 내 리거나 문제점을 수정할 수 있는 독립된 네트워크 포트 를 확보하여 시스템에 포함하였다. 이는 운영체제의 상 태와 서버의 전원 인가 여부에 관계없이 접속하여 복구 작업을 할 수 있도록 돕기 위함이다.

측광 파이프라인 시스템은 안정성 보다는 자료의 입 출력 속도 향상에 중점을 두고 구성하였다. 즉 $640 \mathrm{MB}$ 크기의 관측 이미지 1 장을 처리하는 과정에 다른 서버 로 파일을 전송할 때 사용되는 $\mathrm{HDD}$ 와 네트워크의 입 
표 1. 측광 데이터베이스 서버와 측광 파이프라인 서버의 사양

\begin{tabular}{|c|c|c|}
\hline & 측광 데이터베이스 서버 & 측광 파이프라인 서버 \\
\hline CPU & $\begin{array}{c}\text { Intel } \\
\text { 6-Core Xeon } \\
\mathrm{X} 56502.66 \mathrm{GHz} \times 2 \\
\end{array}$ & $\begin{array}{cl}\text { Intel } & \text { 6-Core Xeon } \\
\mathrm{X} 5650 & 2.66 \mathrm{GHz} \times 2 \\
\end{array}$ \\
\hline 노드 수 & 3 & 3 \\
\hline RAM & 12 GB/node & 24 GB/node \\
\hline HDD & $\begin{array}{c}140 \text { GB } \\
\text { (SAS } 6 \text { Gbps, } 10 \text { KRPM) }\end{array}$ & $\begin{array}{c}300 \text { GB } \\
\text { (SAS } 6 \text { Gbps, } 10 \text { KRPM) }\end{array}$ \\
\hline $\begin{array}{l}\text { POWER } \\
\text { SUPPLY }\end{array}$ & $\begin{array}{c}750 \mathrm{~W} \times 2 \text { (Master } \\
\text { node) } \\
450 \mathrm{~W} \times 2 \text { (2 Slave } \\
\text { node) }\end{array}$ & $450 \mathrm{~W}$ \\
\hline OS & Scientific Linux ${ }^{1} 6.1$ & Scientific Linux 6.1 \\
\hline $\begin{array}{l}\text { 성능 } \\
\text { 목표 }\end{array}$ & $\begin{array}{c}\text { 시스템 안정성, 자료입력 } \\
\text { 및 검색 속도 향상 }\end{array}$ & $\begin{array}{c}\text { 자료 전송 및 저장 속도 } \\
\text { 향상 }\end{array}$ \\
\hline
\end{tabular}

표 2. $\mathrm{HDD}$ 와 $\mathrm{SSD}$ 의 쓰기 속도 비교(828 MB)

\begin{tabular}{c|c|c}
\hline \hline 저장장치 & $\begin{array}{c}\text { CentOS }^{2} \mathbf{5 . 7} \\
\text { Linux, 64 bit }\end{array}$ & $\begin{array}{c}\text { Windows 7, } \\
\mathbf{6 4} \text { bit }\end{array}$ \\
\hline $\mathrm{HDD} \rightarrow \mathrm{HDD}$ & $1.1 \mathrm{~s}$ & $12 \mathrm{~s}$ \\
\hline $\mathrm{HDD} \rightarrow \mathrm{SSD}$ & $8.9 \mathrm{~s}$ & $19 \mathrm{~s}$ \\
\hline
\end{tabular}

출력 성능을 높이는데 중점을 뒸다. $\mathrm{HDD}$ 는 Serial Attached SCSI(SAS) 인터페이스와 $6 \mathrm{Gbps}$ 전송대역폭을 사용하고 $10 \mathrm{~K} \mathrm{RPM}$ 으로 고속 회전하는 제품을 장착하 여 자료의 접근속도 및 전송속도를 증가시켰다. SAS 인터페이스는 여러 개의 $\mathrm{HDD}$ 와 인터페이스 카드를 병 렬로 연결하던 기존의 Small Computer Small Interface(SCSI)를 직렬방식으로 연결하여 병목현상을 개 선한 인터페이스로 개인용 PC보다는 서버에 주로 사용 된다. 표 1 에 측광 데이터베이스 서버와 측광 파이프라 인 서버의 사양을 정리하였다.

특히 서버 구성에 일반 $\mathrm{HDD}$ 를 사용하였는데, $\mathrm{SSD}$ 를 사용하지 않고 $10 \mathrm{KRPM}$ 의 고회전 $\mathrm{HDD}$ 를 선택한 것은 시험 결과 $\mathrm{SSD}$ 의 경우 자료를 읽는 속도는 빠르 지만 $\mathrm{HDD}$ 보다 쓰는 속도가 느려 쓰기 작업이 많은 자 료처리에서는 SSD가 큰 이점이 없기 때문이다. 표 2는 리눅스와 윈도우 시스템에서 $828 \mathrm{MB}$ 의 자료를 $\mathrm{SSD}$ 와

1 Scientific Linux는 페르미 연구소와 유럽핵입자물리연구소 및 기타 대학과 연구기관에 의해 개발, 배포되는 무료 배포판 으로 RehHat Enterprise Linux와 호환된다.

2 CentOS Linux는 자체 커뮤니티에 의해 관리되는 운영체제로 RehHat Enterprise Linux의 소스 코드를 이용하여 개발 및 배포된 다.

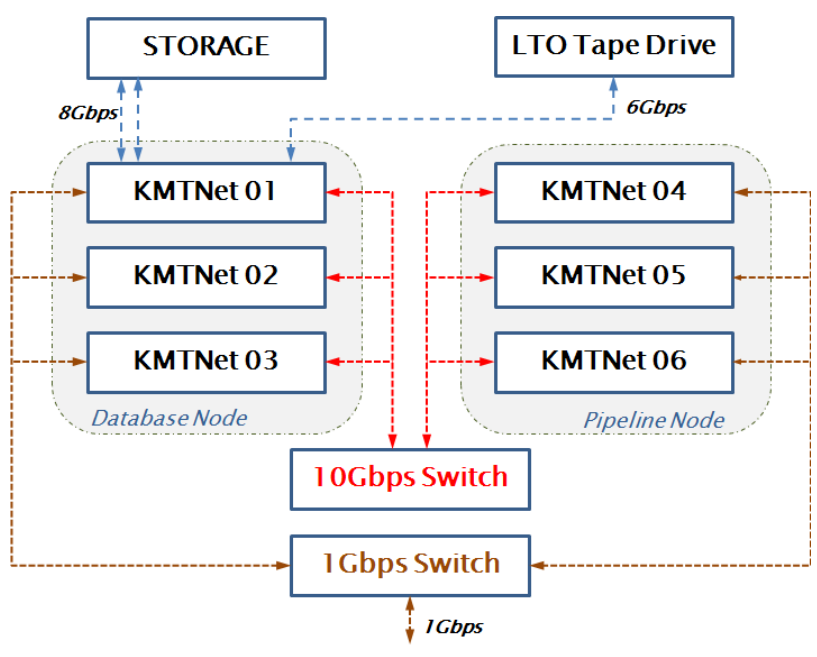

그림 2. 시험운영 서버와 네트워크 구성도. 저장장치는 8 Gbps Fiber Channel, LTO 테이프 드라이브는 $6 \mathrm{Gbps}$ 로 연결하였고, 서버는 $10 \mathrm{Gbps}$ 네트워크로 연결하였다.

$\operatorname{HDD}(7.2 \mathrm{KRPM})$ 에 저장할 때 소요된 시간으로, 실험에 사용한 모든 저장장치는 $3 \mathrm{Gbps}$ 의 포트에 연결하였다. 이 실험으로 운영체제에 따라 속도의 차이는 있지만 $\mathrm{SSD}$ 의 쓰기 속도가 $\mathrm{HDD}$ 보다 느린 것을 볼 수 있다.

시험운영 서버에 사용할 네트워크로 내부망은 10 Gbps, 외부망은 $1 \mathrm{Gbps}$ 로 연결하였다. 내부망은 주로 파일 전송과 외부 저장장치를 Network File System(NFS) 로 연결하는데 사용된다. 그림 2는 시험운영 서버와 네 트워크 구성도이다.

\section{2. 외부 저장장치}

KMTNet의 핵심 연구주제인 중력렌즈 현상을 이용한 외계행성 탐색에 사용되는 총 저장용량은 수 PetaByte(PB)에 이른다. 이러한 저장용량은 그 양이 너 무 방대하여 데이터베이스 시스템이나 파이프라인 시스 템 자체에 $\mathrm{HDD}$ 를 부착하여 구성하기는 매우 어렵기 때문에 별도의 저장장치를 구성한 후 SAS, Fiber Channel(FC) 또는 iSCSI 인터페이스 등으로 연결한다. 한편 외부 저장장치를 구축할 때는 저장용량의 확장성, 자료 흐름의 병목현상 및 여러 서버가 하나의 저장장치 에 연결되었을 경우 발생하는 파일의 신뢰성 등이 충분 히 검토되고 고려되어야 한다.

특히 이번 연구에서는 외부 저장장치 구성을 위해 $\mathrm{HDD}$ 를 한꺼번에 구입하지 않고, 필요할 때마다 용량을 증가시킬 수 있는 방식을 도입하여 확장성을 높였다. 또한 확장성 이외에도 외부 저장장치에는 수십 수백 개의 $\mathrm{HDD}$ 를 장착하여 RAID로 구성하기 때문에 컨트 


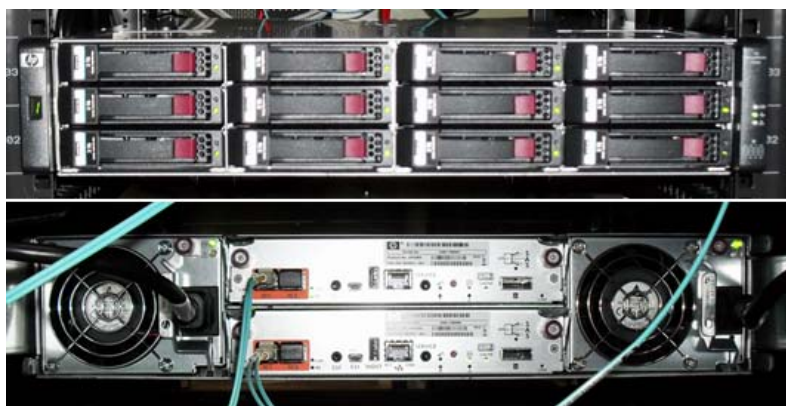

그림 3. 외부 저장장치 및 인터페이스 모듈. 총 12 개 의 $\mathrm{HDD}$ 를 장착할 수 있고, 2 개의 컨트롤러 모듈 을 장착하여 2중화 구성을 하였다.

롤러의 성능과 서버와 연결하기 위한 인터페이스 지원 도 충분히 고려되어야 한다.

이번 구성은 시험운영을 위한 시스템 구축이므로 최 소 단위 저장장치 개념을 도입하였다. 최소 단위 저장 장치는 인클로저 단위로 확장이 가능하고, 하나의 인클 로저에 $6 \mathrm{Gbps}$ 전송대역폭을 지원하는 12 개의 7.2 KRPM 2 TB HDD를 장착하여 RAID 5로 구성하였다. 인클로저에는 2 개의 컨트롤러 및 인터페이스 모듈을 장 착하여 확장 시 발생할 수 있는 문제 해결능력을 높였 다. 2개의 컨트롤러는 failover로 설정되어 A 컨트롤러 가 작동 중 하드웨어 고장을 일으키면 $\mathrm{B}$ 컨트롤러는 대기 상태에서 깨어나 A 컨트롤러 기능을 그대로 넘겨 받게 된다. 컨트롤러뿐만 아니라 FC로 연결된 인터페이 스도 이중화로 구성하여 failover로 작동한다. 그리고 독 립된 전원으로 2 중 구성하여 하드웨어 문제나 정전에 의한 자료 손실을 최소화하였다. 인클로저는 최대 8대 의 단위 저장 장치까지 확장 설치할 수 있어 최대 96개 의 $\mathrm{HDD}$ 를 장착할 수 있다.

서버와 외부 저장장치는 $8 \mathrm{Gbps}$ 를 지원하는 $\mathrm{FC}$ 인 터페이스로 구성하였고, 서버에는 PCI-Ex(ver 2.0) $8 \mathrm{x}$ 전송대역폭(양방향 $8 \mathrm{Gbps}$ )을 사용하는 Host Bus Adapter(HBA)를 장착하여 자료 전송시 병목현상이 발생 하지 않도록 하였다. 그림 3은 도입한 단위 저장장치로 총 $16 \mathrm{~TB}$ 의 저장용량을 갖는다.

\section{3. 개방선형테이프(LTO)와 ASPERA P2P}

남반구 관측소에서 얻은 관측 자료는 천문연구원으로 옮겨져서 처리 - 분석될 계획이다. KMTNet 망원경은 칠 레, 남아프리카 공화국, 호주에 설치되며, 칠레를 제외 한 2곳은 국제 백본망 또는 현지 관측소의 네트워크 사 정이 열악하기 때문에 관측 자료를 항공우편을 통해 수 집할 계획이다. 또한 칠레는 네트워크 전송이 불가능할 경우를 대비한 비상 계획도 함께 수립하여야 한다. 따
라서 관측 자료를 어떤 저장매체에 담아서 보낼지에 대 한 충분한 검토가 이루어져야 한다. 현재 널리 사용되 는 저장매체로 $\mathrm{HDD}$ 와 테이프의 두 가지를 고려할 수 있는데 $\mathrm{HDD}$ 는 전송 속도가 빠르고 $\mathrm{PC}$ 에 쉅게 연결할 수 있다는 장점이 있지만, 고속의 구동부와 전자부품이 포함되어 있어 충격에 취약하고 무겁다는 단점이 있다. 테이프는 크기가 작아 이동이 쉽고 $\mathrm{HDD}$ 무게의 $1 / 3$ 로 가벼운 장점이 있지만, 자료를 읽기 위한 전용 테이프 드라이브가 필요하고 저장 속도가 느린 단점이 있다. 우리는 KMTNet에서 사용할 저장매체로 이 두 가지의 장단점을 보완한 $\mathrm{LTO}$ 를 사용하기로 하였다.

개방선형테이프(Linear Tape-Open; LTO)는 고속 데이 터 처리와 대용량 형식으로 만들어진 백업용 테이프로 자동 오류보정 장치, 오류정정 코드, 하드웨어 데이터 압축, 트랙 레이아웃 기능을 가지고 있다. 2 개의 릴이 달려있는 기존의 DAT 테이프 카트리지 형식과 다르게 1 개의 릴만 있으며, 최근에는 LTO-4와 LTO-5 규격이 사용된다.

KMTNet 시험운영 서버에서 관측자료 백업 및 자료 전송용으로 도입한 LTO-5 테이프 드라이브는 $1.5 \mathrm{~TB}$ (압축 저장 시 $3 \mathrm{~TB}$ )의 저장 공간과 $140 \mathrm{MB} / \mathrm{s}$ 의 자료 전송 속도를 제공하며 LTFS(Linear Tape File System)의 파일 시스템을 지원한다. $6 \mathrm{Gbps}$ 의 SAS 인터페이스로 연결하여 테이프 드라이브와 서버간의 자료전송대역을 충분히 확보하였다.

LTFS는 LTO 드라이브 및 미디어 테이프를 일반적 인 디스크 파일 시스템과 유사하게 사용할 수 있도록 테이프 저장장치를 파티셔닝하는 것으로, $\operatorname{tar}$ 명령을 이 용하여 순차적으로 자료를 기록하는 전통적인 테이프 백업 방식과 다르게 $\mathrm{HDD}$ 와 같이 독립된 저장 공간으 로 인식시켜 $\mathrm{ls}, \mathrm{cp}, \mathrm{mv}, \mathrm{rm}$ 등의 리눅스 명령으로 자료 를 관리할 수 있다. LTFS로 인식된 LTO 테이프는 크게 두 개의 파티션 구조로 이루어진다. 첫 번째 인덱스 파 티션에는 파일에 대한 인덱스 정보가 들어가고, 두 번 째 데이터 파티션에는 파일이 들어가는 구조이다. 파일 에 대한 읽기 요청이 들어오면 첫 번째 파티션의 인덱 스 정보를 통해 파일의 위치를 찾아내고, 두 번째 데이 터 파티션에서 실제 파일을 찾아 읽어오게 된다. 파일 을 삭제할 경우 데이터 파티션의 자료를 삭제하지 않고 인덱스 파티션에서의 정보만 삭제하게 된다. 그리고 파 일을 덮어쓰는 경우 $\mathrm{HDD}$ 와 달리 기존 파일이 있던 자 리 위에 덮어쓰지 않고 자료가 저장된 마지막 지점에 저장하게 되므로 일반 $\mathrm{HDD}$ 처럼 읽고 쓰는 작업이 많 을 때는 LTO 테이프가 적합하지 않지만, KMTNet처럼 단순한 파일의 복사에는 Write Once Read Many(WORM) 형태의 LTO 테이프가 적합하다.

관측소의 네트워크 백본망이 잘 구축되어 있다면 네 
표 3. 개발 시스템에 따른 I/O 벤치마크(sysbench, ext4)

\begin{tabular}{c|c|c|c}
\hline \hline 구분 & $\begin{array}{c}\text { KMTNet } \\
\text { 프레임워크 } \\
\text { 개발시스템 }\end{array}$ & $\begin{array}{c}\text { 데이터베이스 } \\
\text { (시험운영서버) }\end{array}$ & $\begin{array}{c}\text { 측광파이프라인 } \\
\text { (시험운영서버) }\end{array}$ \\
\hline $\begin{array}{c}\text { 초당 요청개수 } \\
\text { (Requests/s) }\end{array}$ & 78.93 & 273 & 393 \\
\hline $\begin{array}{c}\text { 초당 처리량 } \\
(\mathrm{MB} / \mathrm{s})\end{array}$ & 1.23 & 4.26 & 6.14 \\
\hline
\end{tabular}

트워크로 자료를 전송하는 방법을 사용할 수 있다. 네 트워크로 전송하면 받는 즉시 관측 자료를 처리하여 결 과를 볼 수 있는 장점이 있다.

네트워크로 자료를 가져오기 위해서는 일반적으로 FTP 프로토콜을 사용한다. FTP는 21번 포트를 사용하 며 자료전송 시 패킷 단위로 데이터를 묶어서 전송하며 보낸 패킷이 정상적으로 수신되면 다음 패킷을 보내게 된다. 만약 수신 과정에서 에러가 검출되면 해당 패킷 을 재송신하라고 명령하게 된다. 이러한 과정을 통해 에러가 없는 정상적인 파일을 수신할 수 있다. 그러나 이런 과정을 거치면서 시간적인 손실이 발생하고 전송 대역을 전부 사용하지 못하는 문제점이 발생한다. UDP 프로토콜의 경우 FTP와 다르게 에러 보정기능이 없기 때문에 파일 전송을 매우 빠르게 할 수 있다는 장점이 있지만, 전송하는 도중에 에러가 발생하면 손상된 부분 을 재전송하지 않아 전송이 완료된 파일은 손상된 상태 로 있게 된다.

KMTNet에서 도입한 ASPERA P2P는 UDP의 단점을 보완하기 위해 UDP 프로토콜에 에러보정 기능을 추가 한 프로그램으로 백본망이 좋다면 지정한 전송대역폭을 모두 활용하여 자료를 보낼 수 있다. ASPERA P2P는 서버와 클라이언트가 $1: 1$ 접속으로 이루어지며 최대 $45 \mathrm{Mbps}$ 의 전송대역폭을 사용할 수 있다. 한 관측소에 서 하루 동안 약 $150 \mathrm{~GB}$ 의 관측 자료에 대해 $45 \mathrm{Mbps}$ 전송대역폭을 모두 사용하면 8시간 만에 자료를 모두 가져올 수 있다.

ASPERA P2P를 사용할 경우 지진으로 인한 국제 백 본망 손상이나 현지 관측소의 문제로 파일 전송이 불가 능한 경우를 대비한 비상계획을 수립하여야 한다. 각 관측소에는 $16 \mathrm{~TB}$ 용량의 저장장치가 설치되어 2달 이 상 관측 자료를 보관할 수 있다. 장비 문제 등으로 인 해 네트워크 회선의 단기간 속도저하 또는 접속불량이 발생할 경우 해당 자료는 네트워크가 정상화 된 후 재 전송을 할 수 있다. 만약 지진 등으로 국제 백본망이 끓어져 대륙 간 우회를 해야 하는 상황이 발생하면 장 기간 네트워크를 통해 자료를 받는 것이 매우 어려워진 다. 그래서 칠레 관측소에는 측광 자료처리 서버를 설 치하여 산출된 결과 파일을 네트워크로 보내고 관측 자
표 4. 시험운영서버 저장장치에 따른 $\mathrm{I} / \mathrm{O}$ 벤치마크(sysbench)

\begin{tabular}{c|c|c|c}
\hline \hline 구분 & $\begin{array}{c}\text { 내부 저장장치 } \\
\text { (Database Node) }\end{array}$ & $\begin{array}{c}\text { 외부 저ㅈㅏㅏ장칙 } \\
\text { (Fiber Channel) }\end{array}$ & $\begin{array}{c}\text { 외부 저장장치 } \\
\text { (10 Gbps/NFS) }\end{array}$ \\
\hline $\begin{array}{c}\text { 초당 요청개수 } \\
\text { (Requests/s) }\end{array}$ & 273 & 253 & 239 \\
\hline $\begin{array}{c}\text { 초당 처리량 } \\
\text { (MB/s) }\end{array}$ & 4.26 & 3.95 & 3.74 \\
\hline
\end{tabular}

료는 LTO-5 테이프로 보내는 방법을 고려하고 있다.

\section{3. 시험운영 서버 성능 실험}

본 연구를 위해 구성한 시험운영 서버 및 저장장치의 성능을 확인하기 위하여 자료 입출력, 자료백업 및 전 송, 데이터베이스 운영 등의 실험을 실시하였고, 구성한 시스템의 성능을 평가하였다.

\section{1. 자료 입출력 실험}

시험운영 서버의 입출력 속도를 측정하기 위하여 sysbench 프로그램을 이용하였다. 이 프로그램은 MySQL 데이터베이스 라이브러리와 연동하여 특정한 크기의 임 시데이터를 생성한 후 무작위로 읽기/쓰기를 반복하여 저장장치가 초당 처리할 수 있는 작업의 요청수와 초당 처리량이 얼마나 되는지 확인할 수 있다. 표 3은 KMTNet 프레임워크 개발 시 사용한 시스템(김동진 등, 2011)과 시험운영 서버의 벤치마크 결과로, ext4 파일 시스템을 기반으로 테스트하였다.

입출력 속도 시험 결과 측광 데이터베이스 시스템은 프레임워크 개발 서버보다 약 4 배 이상 빠르고, 측광 파이프라인 서버는 6 배가 빠른 것을 확인하였다. 이와 함께 저장장치의 종류에 따른 벤치마크 결과를 표 4에 정리하였다. 외부 저장장치의 속도는 서버의 $\mathrm{HDD}$ 에 비 해 약 $10 \%$ 정도 낮은 속도를 보여준다. 이는 외부 저 장장치의 경우 전송대역폭이 서버의 $\mathrm{HDD}$ 와 비슷해도 $7.2 \mathrm{KRPM}$ 의 회전속도를 가지는 $\mathrm{HDD}$ 를 사용했기 때문 에 자료를 읽고 쓰는 속도가 느린 까닭으로 여겨진다. 한편 외부 저장장치의 경우 6 대의 시험운영 서버 중 1 대만 FC 인터페이스로 연결하였고 다른 서버는 10 Gbps 네트워크 기반에 NFS로 연결하여 충분한 대역폭 을 확보하였기 때문에 NFS로도 FC 인터페이스와 비교 하여 비슷한 속도를 확보하였다.

네트워크 속도에 따른 자료의 전송속도를 표 5에 정 리하였다. scp 명령어로 $828 \mathrm{MB}$ 의 파일을 $1 \mathrm{Gbps}$ 와 10 Gbps 네트워크에서 각각 전송하였을 경우 특별한 속도 차이는 발생하지 않았다. scp는 암호화 기능이 포함된 복사 명령어로 다른 서버로 자료전송 시 암호화 하는 과정으로 인해 고속 네트워크에서 전송속도의 향상이 
표 5. 네트워크 따른 전송속도 벤치마크(828 MB)

\begin{tabular}{c|c|c}
\hline \hline 네트워크 속도 & $\mathrm{scp}$ 명령어 & $\mathrm{ftp} / \mathrm{ncftp}$ 명령어 \\
\hline $1 \mathrm{Gbps}$ & $18.00 \mathrm{~s}$ & $7.43 \mathrm{~s}$ \\
\hline $10 \mathrm{Gbps}$ & $18.00 \mathrm{~s}$ & $1.41 \mathrm{~s}$ \\
\hline
\end{tabular}

없었다. 그러나 $\mathrm{ftp}$ 나 $\mathrm{ncftp}$ 와 같이 일반 프로토콜을 사 용할 경우 $10 \mathrm{Gbps}$ 의 네트워크가 $1 \mathrm{Gbps}$ 보다 전송속도 에 있어 6 배 이상 빨랐다. 동일한 파일을 $10 \mathrm{KRPM}$ $\mathrm{HDD}$ 에서 복사할 경우 $0.7 \sim 0.8$ 초가 소요되는 것에 비 교하면 $10 \mathrm{Gbps}$ 의 경우 $\mathrm{HDD}$ 속도에 근접하는 것을 볼 수 있다. 즉 $10 \mathrm{Gbps}$ 네트워크를 사용한다면 자료를 전 송할 때 발생하는 시간 지연을 충분히 해결할 수 있을 것이다. KMTNet 시험운영 서버의 내부 자료전송은 스 크립트 구성이 가능한 $\mathrm{ncftp}$ 와 $10 \mathrm{Gbps}$ 네트워크를 사 용하는 것이 최선이라 판단된다.

표 6은 기존 측광 파이프라인 개발 시스템과 시험운 영 측광 파이프라인 시스템과의 네트워크 파일 전송 및 복사 실험의 결과이다. 시험운영 측광파이프라인 시스 템은 기존 시스템과 비교하여 파일 전송은 8 배, 복사는 5 배 빠른 결과를 보였고, 시스템의 구축 성능 목표를 충분히 만족하였다.

\section{2. 개방선형테이프(LTO) 전송속도}

KMTNet 관측소에서 관측 자료를 보내기 위해 사용할 LTO-5 테이프와 HDD의 자료 백업 속도를 비교하였다. 한 관측소에서 하룻밤에 생성되는 관측 자료는 약 190 $\mathrm{GB}$ 이지만 약 $10 \%$ 더 많은 용량인 $203 \mathrm{~GB}$ 로 가정하여 모의자료를 생성하였고, 이 자료를 외부 저장장치에서 백업 미디어로 복사하는 과정을 각각 5회 반복하였다. 외부 저장장치는 $8 \mathrm{Gbps} \mathrm{FC}$ 인터페이스로 연결하였고, LTO-5 테이프는 $6 \mathrm{Gbps} \mathrm{SAS}$ 인터페이스로 연결하였다. LTO-5와 비교할 백업 미디어로는 SATA-2 $\operatorname{HDD}(3 \mathrm{G}$ bps, $7.2 \mathrm{KRPM}, 1 \mathrm{~TB}$ )을 사용하였고 e-SATA 인터페이 스로 연결하였다. 표 7은 LTO-5 테이프와 $\mathrm{HDD}$ 의 저장 시간 측정 결과이다.

리눅스의 $\mathrm{cp}$ 명령으로 외부 저장장치에서 $\mathrm{HDD}$ 로 자료를 복사할 경우 평균 39.34분의 시간이 소요되었고, $\mathrm{HDD}$ 에서 외부 저장장치로 자료를 다시 복사할 경우 33.34분의 시간이 소요되었다. 외부 저장장치에서 LTFS 파일시스템을 사용한 LTO-5 테이프로 자료를 복사할 경우 51.22분의 시간이 소요되었으며, LTO-5 테이프에 서 외부 저장장치로 복사할 경우 37.41 분이 소요되었다. 기존 백업방식인 $\operatorname{tar}$ 명령어로 LTO-5 테이프에 복사하
표 6. 측광파이프라인 시스템에 따른 관측이미지의 파일 전송 및 복사 실험 $(828 \mathrm{MB})$

\begin{tabular}{c|c|c}
\hline \hline 구분 & $\begin{array}{c}\text { 측광파이프라인 } \\
\text { 개발시스템 }(2009)\end{array}$ & $\begin{array}{c}\text { 측광파이프라인 } \\
\text { (시험운영서버) }\end{array}$ \\
\hline $\begin{array}{c}\text { 파일 전송 } \\
\text { (ftp/nctp) }\end{array}$ & $\begin{array}{c}11 \mathrm{~s} \\
(1 \mathrm{Gbps} \text { 사용 })\end{array}$ & $\begin{array}{c}1.4 \mathrm{~s} \\
(10 \mathrm{Gbps} \text { 사용 })\end{array}$ \\
\hline $\begin{array}{c}\text { 파일 복사 } \\
(\mathrm{cp})\end{array}$ & $8.71 \mathrm{~s}$ & $1.7 \mathrm{~s}$ \\
\hline
\end{tabular}

표 7. 외부 저장장치와 $\mathrm{LTO}-5$ 테이프・ $\mathrm{HDD}$ 의 자료 저장 속도

\begin{tabular}{c|c|c}
\hline \hline 저장매체 & 저장시간 & 속도 \\
\hline $\begin{array}{c}\text { 외부 저장장치 } \rightarrow \\
\text { SATA-2 HDD (7,200 RPM) }\end{array}$ & 39.34 분 & $89.12 \mathrm{MB} / \mathrm{s}$ \\
\hline $\begin{array}{c}\text { SATA-2 HDD (7,200 RPM) } \\
\rightarrow \text { 외부 저장장치 }\end{array}$ & 33.34 분 & $105.95 \mathrm{MB} / \mathrm{s}$ \\
\hline $\begin{array}{c}\text { 외부 저장장치 } \rightarrow \\
\text { LTO-5 테이프 }\end{array}$ & 51.22 분 & $67 / 65 \mathrm{MB} / \mathrm{s}$ \\
\hline $\begin{array}{c}\text { LTO-5 테이프 } \rightarrow \\
\text { 외부 저장장치 }\end{array}$ & 37.41 분 & $91.90 \mathrm{MB} / \mathrm{s}$ \\
\hline \multicolumn{2}{|c|}{}
\end{tabular}

였을 경우 전송속도가 약 $30 \mathrm{MB} / \mathrm{s}$ 로 100 분 이상의 시 간이 소요되었다.

자료를 외부 저장장치에서 $\mathrm{HDD}$ 와 LTO-5로 저장할 경우 LTO-5 테이프가 HDD보다 약 25\% 속도가 떨어지 는 것을 확인할 수 있다. 하지만 백업미디어에서 다시 자료를 불러오는 경우에는 HDD가 LTO-5 테이프에 비 해 약 $10 \%$ 정도 빠른 결과를 보였다. 이것은 LTO-5 테 이프의 자료 저장 속도가 $\mathrm{HDD}$ 에 비해 현저히 떨어지 지 않고, 읽기 성능은 $\mathrm{HDD}$ 와 거의 동일하다는 것을 의 미한다. 그러므로 LTO-5 자체의 장점을 고려하면, $\mathrm{HDD}$ 를 대체하여 현지 관측소에서 자료를 백업하여 발송하 기 위한 미디어로 LTO-5가 매우 적합하다고 판단된다.

\section{3. 데이터베이스 실험}

우리가 구성하고자 하는 측광 데이터베이스 시스템은 자료 저장과 동시에 검색 서비스까지 수행해야하기 때 문에 하나의 테이블을 이용하여 시스템을 구성하는 것 은 불가능하다. 따라서 이를 해결하기 위해서는 데이터 베이스 시스템을 병렬화 또는 분산화 하는 작업을 거쳐 야 한다. 병렬화는 데이터베이스 기능을 복수의 서버가 하나의 시스템처럼 작동하도록 공유하는 방식으로 핫 백업 기능이 있기 때문에 한 대의 서버가 다운되더라도 데이터베이스 기능에는 큰 문제가 발생하지 않는다. 그 


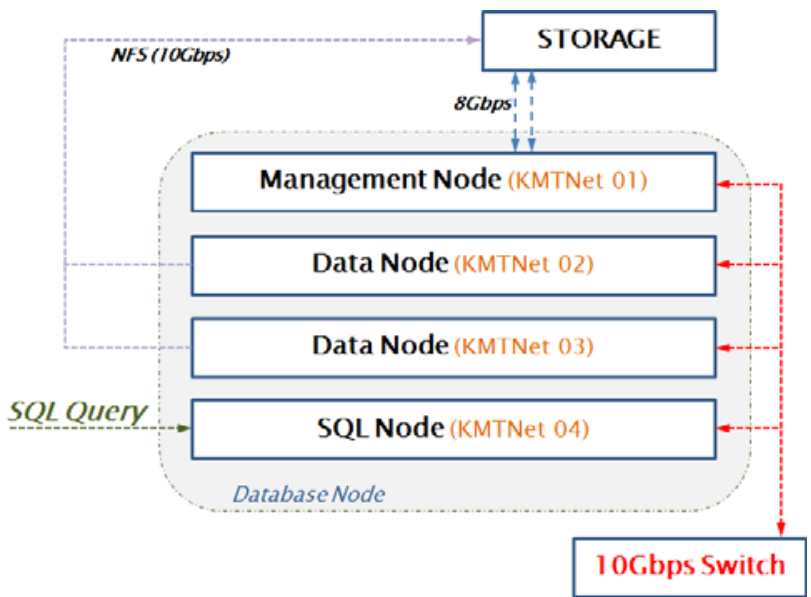

그림 4. MySQL 병렬데이터베이스 구성도. 관리 노드 1 대, 데이터 노드 2 대, SQL 노드 1 대로 구성하였고, 10 Gbps 네트워크로 연결하였다.

러나 분산화는 데이터베이스의 테이블을 여러 서버로 분할하는 방식이기 때문에 한 대의 서버가 다운될 경우 그 서버가 가지고 있는 자료는 검색할 수 없다.

병렬화를 지원하는 데이터베이스는 ORACLE, MySQL, MS-SQL, CUBRID 등 여러 제품이 존재하지만, 김동진 등(2011)이 KMTNet 프레임워크 개발에 사용하 였던 MySQL을 이용하여 병렬 데이터베이스 구성을 하 였다. 시험운영을 위해 구성한 시스템의 MySQL 병렬 데이터베이스를 구성하기 위해서는 최소 4대의 서버가 필요하다. 모든 노드의 상태 및 기능 전환을 지시하기 위한 관리 노드 1 대와 입력되는 자료가 저장될 데이터 노드 2 대, 검색 질의 및 자료 입력 명령이 수행되는 $\mathrm{SQL}$ 노드 1 대 등이다. 규모에 따라 데이터 노드와 SQL 노드를 추가할 수 있고 최대 63대까지 확장할 수 있다. 그림 4는 이 실험에서 구성한 MySQL의 병렬 데이터베 이스 시스템 구성도이다.

MySQL 병렬 데이터베이스의 특징은 병렬 구성 전 용 검색엔진인 NBD Cluster를 사용해야 하고, 데이터 노드에 저장되는 자료는 스토리지 공유 방식이 아닌 백 업 방식으로 작동된다. 자료를 입력할 경우 각각의 데 이터 노드에 동일한 자료가 입력되기 때문에 하나의 데 이터 노드가 다운되어도 다른 데이터 노드에서 동일한

$3 \mathrm{NDB}$ Cluster는 MySQL 의 병렬클러스터를 지원하는 저장엔진 으로, 중복성과 부하분산 기능을 하도록 생성되었고, 트랜 잭션 기능을 지원한다. 데이터 노드의 데이터를 공유하지 않는다.

4 InnoDB는 트랜잭션을 처리하기 위해 개발된 저장엔진으로 안전성과 자동장애복구 기능이 우수하다.

$5 \mathrm{MySQL}$ 에 포함된 가장 오래된 저장엔진으로 빠른 입출력 및 검색 속도를 가지나, 트랜잭션 기능을 지원하지 않는다.
표 8. 저장엔진에 따른 자료 입력시간(단위: 초)

\begin{tabular}{c|c|c|c|c}
\hline \hline & 레코드 수 & NDB Cluster $^{3}$ & InnoDB4 $^{4}$ & MyISAM5 \\
\hline $1-30$ 일 & $62,004,960$ & $25,164.37$ & $12,950.11$ & 348.13 \\
\hline $31-60$ 일 & $62,004,960$ & $25,634.05$ & $13,290.72$ & 946.88 \\
\hline $61-90$ 일 & $62,004,960$ & $25,705.24$ & $13,268.79$ & $1,073.67$ \\
\hline $91-120$ 일 & $62,004,960$ & $25,600.21$ & $13,345.05$ & 979.56 \\
\hline $121-150$ 일 & $62,004,960$ & $25,837.46$ & $13,536.78$ & 976.48 \\
\hline
\end{tabular}

서비스가 가능하지만 저장 공간이 데이터 노드 수만큼 요구되기 때문에 병렬 데이터베이스로 KMTNet을 장기 간 운영할 경우 외부 저장장치의 구입비용은 데이터 노 드의 수만큼 증가하게 된다.

우리가 구성한 시스템을 이용하여 데이터베이스 저 장엔진에 따른 자료 입력시간을 실험하였다. 실험에 사 용한 자료는 $\mathrm{MOA}$ 그룹이 2006년 3월 29일부터 2007년 9월 16 일까지 관측한 R-band 자료를 사용하였다(김동진 등, 2011). $2 \mathrm{~K} \times 4 \mathrm{~K}$ 의 영상을 32 개의 $512 \times 512$ 영역으 로 분할한 이미지 중 하나를 측광처리한 후 RANDOM 함수를 이용하여 5년 동안의 가상 자료를 생성하였다. 이 자료는 1 년 중 약 200 일 동안 관측을 수행하고, 512 $\times 512$ 영역에 14,353개의 별이 있다고 가정하였다. 영 상을 $512 \times 512$ 크기로 자른 이유는 관측 자료의 왜곡 효과 등에 의한 영향을 받지 않는 최적의 크기라 판단 했기 때문이다. 표 8은 모의자료를 30일씩 묶어 150 일 동안의 자료를 데이터베이스에 입력한 결과이다. 입력 에 사용된 30 일치의 자료는 6,200 만 레코드를 가지고 있고 크기는 $6.2 \mathrm{~GB}$ 이다.

MyISAM 저장엔진은 업로드 수행시간이 20분 미만 으로 가장 빨랐고, InnoDB의 입력 속도는 3시간 40 분이 었다. NDB Cluster는 SQL 노드에서 데이터 노드로 연 결된 네트워크를 통하여 자료가 저장되었고, 2대의 데 이터 노드에 각각 저장되기 때문에 7시간이 넘는 시간 이 소요되어 병렬화를 수행했을 때 시간이 많이 소요되 었다. 병렬화의 장점은 안정성과 로드 밸런싱 능력이다. 그러나 자료 저장에 많은 시간이 소요되어 제때 자료를 데이터베이스에 올리지 못하고 활용하지 못한다면 이러 한 장점은 큰 의미가 없다. 그러므로 $\mathrm{KMTNet}$ 의 측광 데이터베이스는 병렬화보다 관측 영역을 분할하여 데이 터베이스를 분산하는 것이 더 효율적이라고 판단된다.

$\mathrm{KMTNet}$ 에서 사용할 $18 \mathrm{~K} \times 18 \mathrm{~K} \mathrm{CCD}$ 카메라의 관 측 영상을 $512 \times 512$ 영역으로 분할하면 총 1,296 조각 이 된다. 이 조각 중 하나를 측광처리하면 약 $1.5 \mathrm{MB}$ 의 측광결과 파일이 생성되므로, $18 \mathrm{~K} \times 18 \mathrm{~K}$ 전체 영역 에 대한 측광결과 파일 크기는 약 $1.9 \mathrm{~GB}$ 가 된다. 1.9 $\mathrm{GB}$ 의 측광 자료를 데이터베이스에 입력하는 5 가지 경 우에 대한 실험을 수행하였고, 표 9에 5가지 실험의 결 


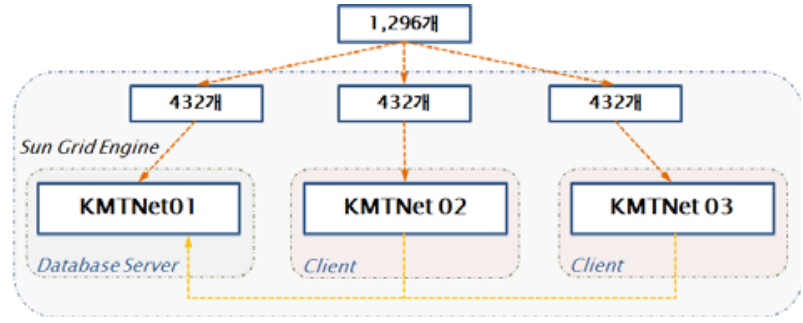

그림 5. 다중 노드에서 job scheduler를 이용한 자료 입력. 1,296 개의 명령을 432 개씩 3 등분하였고, job scheduler를 이 용하여 3대의 데이터베이스 서버에서 각각 실행하였다.

과를 정리하였다.

CASE 1과 CASE 2는 1대의 데이터베이스에서 1,296 조각의 자료를 입력하는 실험이다. 이중 CASE 1 은 데 이터베이스 서버에서 job scheduler 프로그램인 Sun Grid Engine으로 1,296회의 입력 명령을 job queue에 올려 자 료를 입력한 실험이고, CASE 2는 1,296회의 입력 명령 을 단순 반복한 실험이다. 두 경우는 job scheduler의 유 무 차이만 존재하는데 MyISAM 저장엔진의 경우 job scheduler를 사용하였을 경우 약 $130 \%$ 이상의 시간이 더 소요되었고 $\mathrm{InnoDB}$ 저장엔진은 큰 차이가 없었다. MyISAM 저장엔진이 한 조각의 자료를 데이터베이스에 입력하는데 1 초미만의 시간이 소요되고 InnoDB 저장엔 진은 3 초가 소요된다. MyISAM과 job scheduler가 함께 사용되면 자료를 입력하는 시간보다 job scheduler가 다 음 제어명령을 수행하는 시간이 더 길어 입력속도가 느 려진다. 반면 InnoDB는 자료를 입력하는 시간동안 job scheduler가 제어명령을 충분히 처리하므로 입력속도에 큰 차이가 없다.

CASE 3 에서 CASE 5 까지 실험은 1 대의 데이터베이 스와 2 대의 클라이언트를 이용하여 1,296 조각을 분할하 여 입력하는 실험이다. CASE 3은 1,296조각을 job queue에 한꺼번에 올린 후 각 서버로 작업을 분배하여 입력한 실험으로, CASE 1과 실험 방법이 동일하다. 그 러나 job scheduler가 각 서버의 여유자원을 파악하여 작업을 분배하기 때문에 모든 서버에 동일한 수의 작업 이 분배되지는 않는다. CASE 3 은 CASE 1 보다 MyISAM은 입력 시간이 $35 \%$ 정도 감소되었고, InnoDB 도 약 $28 \%$ 감소하였다. 그러나 MyISAM은 여전히 job scheduler를 사용하지 않은 CASE 2보다 입력 시간이 오 래 걸렸다.

CASE 4 는 1,296 개의 조각을 432 개로 분할하여 ssh 명령어로 각 서버가 독립적으로 입력을 실행하도록 하 는 방법으로 CASE 2 를 3 대로 분산한 경우이다. CASE 2에 비해 MyISAM은 55\%, InnoDB는 $75 \%$ 이상 입력 시간이 감소하였다.

CASE 5는 CASE 4의 실험에 job scheduler를 이용하
표 9. 1,296조각의 측광 자료 입력시간(단위: 초)

\begin{tabular}{c|c|c|c|c|c}
\hline \hline \multirow{2}{*}{ 저장엔진 } & CASE 1 & CASE 2 & CASE 3 & CASE 4 & CASE 5 \\
\cline { 2 - 6 } & $\begin{array}{c}\mathbf{1} \text { node } \\
\text { (job } \\
\text { scheduler) }\end{array}$ & $\mathbf{1}$ node & $\begin{array}{c}\text { 3 node } \\
\text { (job } \\
\text { scheduler) }\end{array}$ & $\begin{array}{c}\text { 3 node } \\
\text { (ssh) }\end{array}$ & $\begin{array}{c}\mathbf{3} \text { node } \\
\text { (ssh + job } \\
\text { scheduler) }\end{array}$ \\
\hline MyISAM & 350.83 & 144.87 & 231.96 & 65.89 & 45.75 \\
\hline InnoDB & 640.25 & 645.34 & 465.88 & 160.36 & 115.28 \\
\hline
\end{tabular}

였다. CASE 3 의 실험은 1,296 조각 모두 job queue에 올 리는데 비해 CASE 5는 432조각을 실행하도록 하는 명 령어 3 개를 queue에 올리므로 job scheduler의 제어시간 을 크게 사용하지 않았다.

CASE 5는 CASE 2에 비해 MyISAM은 68\%, InnoDB 는 $82 \%$ 이상 입력 시간이 감소하였다. 그림 5 는 CASE 5 방법으로 자료를 입력하는 흐름도이다.

MyISAM 저장엔진은 InnoDB 저장엔진과 다르게 하 드웨어에 크게 의존하지 않아 빠른 속도로 사용이 가능 하다(김동진 등, 2011). 그러나 자료를 입력하는 동안 테이블 전체에 잠금을 설정하고 작업하기 때문에 검색 이 불가능하고, 반대로 검색을 하는 동안에는 자료 입 력이 불가능하다. 데이터베이스에 저장된 측광자료에서 변광천체를 검출하기 위한 프로그램이 데이터베이스에 연동되어 24시간 실행되는 것을 고려한다면 InnoDB 검 색엔진을 사용하는 것이 바람직하다. 그러나 InnoDB의 여러 장점에도 불구하고 자료 입력 시간이 오래 걸리는 단점 때문에 실제 적용에 어려움이 있었지만, CASE 5 의 방법으로 자료를 입력한다면 InnoDB 검색엔진을 사 용할 때 발생되는 입력시간 지연 문제와 검색 프로그램 의 동시 실행을 모두 해결할 수 있으리라 판단된다.

데이터베이스 실험을 위해 생성한 $512 \times 512$ 영역 의 5년간의 가상자료를 데이터베이스에 모두 입력하면 약 21억 개의 레코드가 생성되고, 용량은 $140 \mathrm{~GB}$ 정도 이다. 대용량의 자료를 빠르게 검색하기 위해서 인덱스 를 사용하였다(김동진 등, 2011). 표 10은 검색엔진과 인덱스 유무에 따른 검색 소요시간이다. 인덱스를 사용 한 MyISAM 저장엔진과 $\mathrm{InnoDB}$ 저장엔진에 따른 검색 시간의 차이는 없었다. 데이터베이스 테이블에 최초 검 색 명령을 실행하면 전체 테이블 정보를 메모리로 캐싱 하는 작업이 이루어져 검색 시간이 증가하였지만 그 이 후 검색부터 1 초미만의 시간이 소요되었다.

KMTNet 프레임워크 개발 시스템의 경우 2,500만개 의 자료를 사용하여 실험을 진행하였지만, 이번 연구에 서는 그보다 100 배 많은 자료를 이용하여 실험하였다. 김동진 등(2011)에 따르면 KMTNet 프레임워크 개발 시 스템의 경우 2,500만 레코드의 자료를 입력하는데 94,000 여 초의 시간이 소요되었다. 그러나, 시험운영 서 
표 10. 저장엔진과 인덱스 사용 유무에 따른 데이터 베이스 검색시간(21억 개 레코드 기준)

\begin{tabular}{|c|c|c|c|}
\hline index & 저장엔진 & 검색 & Searching Time (s) \\
\hline \multirow{4}{*}{ X } & \multirow{2}{*}{ MyISAM } & 최초검색 & 346.21 \\
\hline & & 평균검색시간 & 348.43 \\
\hline & \multirow{2}{*}{ InnoDB } & 최초검색 & 351.47 \\
\hline & & 평균검색시간 & 352.37 \\
\hline \multirow{4}{*}{$\mathrm{O}$} & \multirow{2}{*}{ MyISAM } & 최초검색 & 3.66 \\
\hline & & 평균검색시간 & 0.28 \\
\hline & \multirow{2}{*}{ InnoDB } & 최초검색 & 4.24 \\
\hline & & 평균검색시간 & 0.28 \\
\hline
\end{tabular}

버의 경우 6,200만 레코드의 자료를 입력하는데 13,000 여 초가 소요되었다. 표 3의 결과에서 보듯이 시험운영 데이터베이스 서버는 KMTNet 프레임워크 개발 시스템 보다 3배 이상 빠른 I/O 성능을 가지고 있지만 그 외 CPU와 메모리, 각종 디스크 컨트롤러 등으로 인해 더 욱 큰 성능 차이가 발생한 것으로 보인다. 2,500 만 레코 드의 자료를 입력하였을 경우 시험운영 데이터베이스 서버는 프레임워크 개발 시스템에 비해 18 배 이상의 입 력속도를 보였고, 구축 성능 목표를 만족하였다.

\section{4. 결론 및 토의}

우리는 KMTNet 측광 데이터베이스와 측광 파이프라인 을 시험운영하기 위한 시스템을 구축하였고, 운영 시 발생할 수 있는 문제점을 찾고 이를 보완하기 위한 실 험을 수행하였고 시험운영서버의 구축 성능 목표를 만 족하였는지도 분석하였다.

측광 데이터베이스 시스템은 전원 2중화를 통하여 안정성을 확보하였고 측광 파이프라인 시스템은 입출력 성능의 향상에 중점을 두었다. 외부 저장장치는 $8 \mathrm{Gbps}$ 의 대역폭을 사용하였고, 내부 네트워크 $10 \mathrm{Gbps}$ 를 사 용하는 등 병목현상이 발생할 수 있는 부분을 제거하는 데 중점을 두었다. 그로인해 시험운영용 데이터베이스 서버는 KMTNet 파이프라인 개발 시스템보다 18배 이 상 빠른 성능을 보였고 측광 파이프라인 서버는 기존 시스템에 비해 5 배 이상의 성능을 보였다. 관측소에서 관측 자료를 백업하고 전송할 미디어로 LTO-5 테이프 를 선택하였다. 이 미디어는 $\mathrm{HDD}$ 와 견줄만한 입출력 속도를 보여주었으며 서버 간 호환성 문제도 나타나지 않았을 뿐만 아니라, 전체적인 성능도 KMTNet에서 사 용할 목적에 부합된다고 판단되었다.

KMTNet 관측이 시작된 후 5년이 지나면 $300 \mathrm{~TB}$ 이 상의 데이터베이스가 형성이 되는데, 하나의 노드로 검 색 서비스를 수행하기는 불가능하기 때문에 시험운영 서버의 데이터베이스 병렬화에 대한 실험을 수행하고
결과를 정리하였다. 결과에 의하면 KMTNet은 NDB Cluster를 이용한 데이터베이스의 병렬화보다 MyISAM 이나 InnoDB 저장엔진을 사용하여 관측 영역별로 여러 노드에 데이터베이스를 분산하는 방식이 더 효율적임을 확인하였다. InnoDB 저장엔진은 자료의 입력과 검색이 동시에 가능하여 자료의 입력과 검색이 빈번하게 발생 하는 KMTNet 데이터베이스에 적합하지만, 자료 입력시 간이 오래 걸리는 문제로 KMTNet 프레임워크 개발에 는 속도 위주의 MyISAM 저장엔진을 사용하였다(김동 진 등, 2011). 표 8의 CASE 5 실험 결과처럼 입력 자료 를 분할한 후 여러 서버에서 job scheduler로 입력하는 방법을 사용한다면 InnoDB의 입력 시간을 $1 / 5$ 로 단축시 킬 수 있다. 따라서 KMTNet 데이터베이스 저장엔진을 MyISAM에서 InnoDB로 교체하여 입력과 검색을 동시 에 진행할 수 있도록 하였다.

우리는 이 연구를 통해 시험운영 서버를 구축하고 하드웨어와 소프트웨어의 단계별 성능을 점검하였다. 향후에는 이번에 구축한 시험운영 서버를 기반으로 모 의 관측 자료를 생성하고 시험운영을 실시하여 측광 파 이프라인, 측광 데이터베이스 및 분석모델링 프로그램 이 유기적으로 연동하는지 확인하여야 한다. 그리고 시 험운영 과정에서 도출된 문제점들을 분석하여 실시간 운영 시 문제가 발생하면 즉각 대처할 수 있도록 하여 야 할 것이다.

\section{참고 문헌}

김동진, 이충욱, 김승리, 박병곤, 이재우, 2009, KMTNet 자료처리 시스템 설계와 측광데이터베이스 구축, 천 문학논총, 24, 83

김동진, 이충욱, 김승리, 박병곤, 2011, 중력렌즈 사건 측광 데이터베이스 및 프레임워크 개발, 천문학 논 총, 26,41

이충욱, 박병곤, 김승리, 이재우 등, 2009, 영상차감법을 이용한 대용량탐색자료처리 파이프라인 개발, 한국천 문연구원 기술보고서(No. 20090238)

Bond, I. A., Abe, F., \& Dodd, R. J., et al., 2001, Real-Time Difference Imaging Analysis of MOA Galactic Bulge Observations During 2000, MNRAS, 327, 868

Lee, C. -U., Koo, J. -R., Kim, S. -L., Lee, J., Park, B. -G., \& Han, C., 2010, Detection of Variable Stars in the Open Cluster M11 Using Difference Image Analysis Pipeline, JASS, 27, 289

Schneider, J., Dedieu, C., Le Sidaner, P., Savalle, R., \& Zolotukhin, I., 2011, Defining and Cataloging Exoplanets: the Exoplanet.eu Database, A\&A, 532, A79

Udalski, A., Szymanski, M., Soszynski, I., \& Poleski, R., 2008, The Optical Gravitational Lensing Experiment. 
Final Reductions of the OGLE-III Data, Acta Astronomica, 58, 69

Wolszczan, A. \& Frail, D. A., 1992, A Planetary System Around the Millisecond Pulsar PSR1257+12, Nature, 355, 145 